\title{
Obituary
}

\section{In Memoriam: Georges Tsoucaris}

\section{Philippe Walter ${ }^{1}$, Jerry L. Atwood ${ }^{2}$ and Janusz Lipkowski ${ }^{3, *}$}

1 Sorbonne Université | UPMC, Laboratoire d'Archéologie Moléculaire et Structurale (LAMS), rue de L'école de Médecine, 75006 Paris, France; philippe.walter@upmc.fr

2 Department of Chemistry, University of Missouri-Columbia, Columbia, MO 65211, USA; atwoodj@missouri.edu

3 Faculty of Mathematical and Natural Sciencest, Cardinal Stefan Wyszynski University, 01-938 Warszawa, Poland

* Correspondence: j.lipkowski@uksw.edu.pl

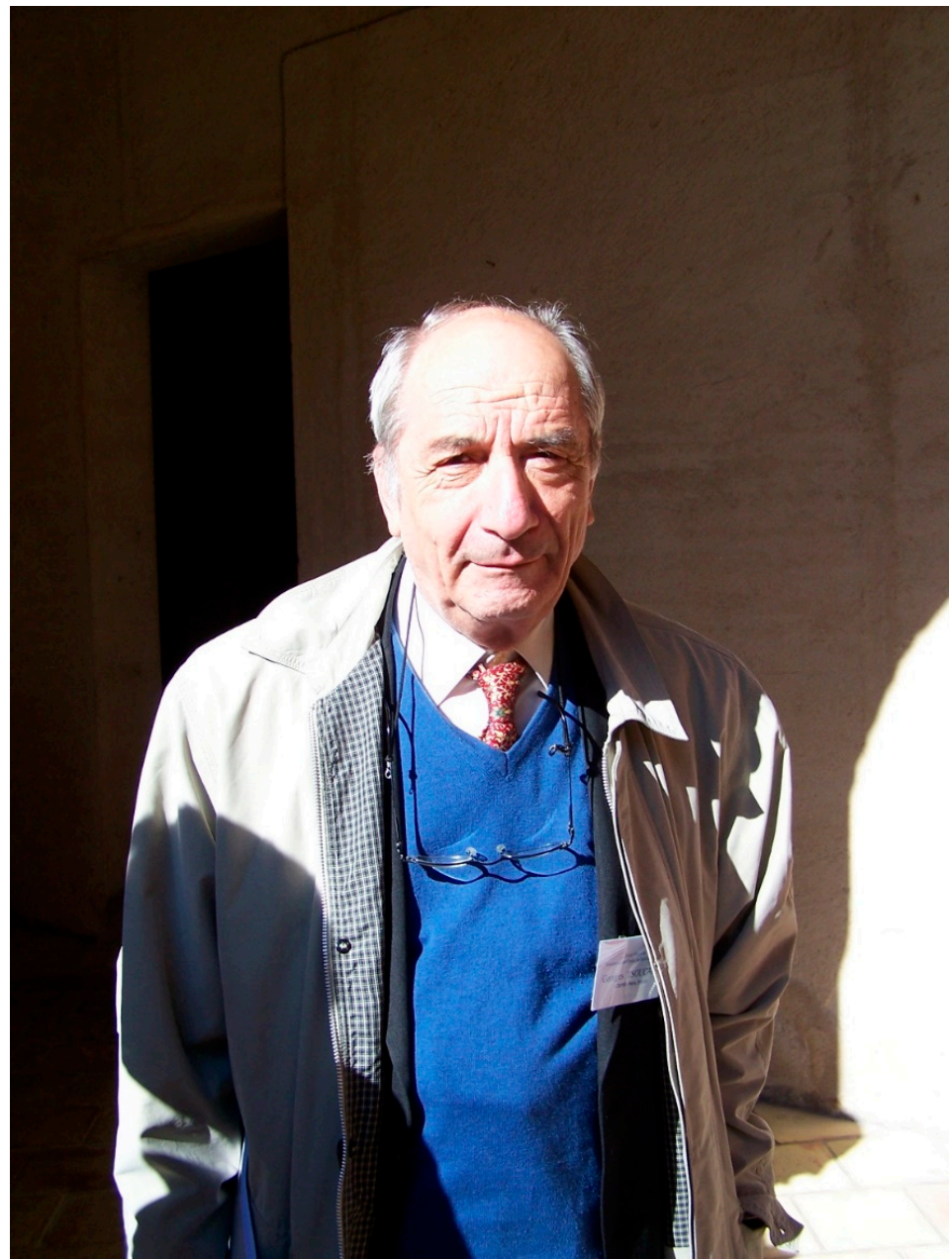

It is with deep sorrow that we announce that on 30 January 2020, Professor Georges Tsoucaris passed away in his home in Paris, after a long illness.

Georges was born in Thessaloniki (Greece), 89 years ago. He received an excellent education in Paris (France), starting at the Ecole Nationale Supérieure de Chimie de Paris, (today Chimie Paristech), where he graduated with a degree in Ingénieur-Chimiste (1954), followed by a PhD at La Sorbonne 
(1959, Docteur-ès-sciences, Faculté des sciences). Then, he combined his university work with work at the French Conseil Nationale de la Recherche Scientifique, where he served as Maitre de Recherche (Associate Professor, since 1962) and Directeur de Recherche DR1 (Professor) for 30 years (1968-1998). Alongside this, he was a Professor at the Ecole Polytechnique (Maitre de Conferences) and CNRS Directeur de l'Unité Propre de Recherche du CNRS UPR 180:1999-2011 C2RMF, Chargé de mission. In 2012, Professor Tsoucaris worked at the Laboratory of Molecular and Structural Archaeology, part of the Louvre Museum in Paris, as a consultant.

The scientific studies of Georges Tsoucaris were broad. One of his major achievements was associated with the development of direct methods in crystallography (Maximum Determinant Rule 1970, with Athanassios Hountas in Athens). His contribution to the structural analysis of dissymmetric organic compounds (with Nneri Kagan) is highly appreciated and also led Georges to supramolecular chemistry (which includes the study of several types of compounds). His wife Danuta (Professor of Pharmaceutical Chemistry) has greatly supported Georges' studies in the field of the structure of biologically active compounds.

A characteristic feature of Professor Tsoucaris' studies was the combination of basic, creative research work with teaching at a high international level. He served as Co-organizer of International Schools in the fields of Crystallography (Direct Methods), Supramolecular Chemistry (with emphasis on chiral discrimination) and Molecular Archaeology. In the last issue, he served as Director of the Hubert Curien Molecular and Structural Archaeology International School in Erice, Sicily. 